status tended to deteriorate slightly less in patients given linoleate than in those receiving oleate supplements, but while this was observed in the Belfast patients it was not found in London. In view of this difference it is impossible to make any useful judgement on whether linoleate treatment is likely to slow deterioration in multiple sclerosis. At first sight it may seem clinically unlikely that a treatment could reduce the severity of relapse but not the overall rate of deterioration, but it must be remembered that the latter will also depend on the extent to which recovery from relapse has taken place. A lack of correlation between relapse severity and long-term effect could also occur if, for instance, the treatment reduced secondary abnormalities at the time of relapse, an analogy being cerebral oedema associated with infarction.

A complication in interpretation is that patients seen in London (particularly those in the control group) had relatively short disease histories. However, even if relapses tend to be more frequent and more severe in patients with short histories we think it unlikely that there would have been as large a difference in severity between the linoleate and oleate treated groups in London as was observed.

The serial fatty acid estimations in the group receiving linoleate confirm the earlier finding (Belin et al., 1971) that there is no defect in the absorption of linoleate, in the doses used, in patients with multiple sclerosis. Despite assurances to the contrary it is possible that the one patient who did not show a rise in the serum linoleate level did not regularly take the supplements.

The dose of linoleate supplement, in the form of a $50 \%$ emulsion, was chosen arbitrarily but has been shown to cause a significant rise of the serum linoleate level. On the other hand, the dose of olive oil taken by the control group was deliberately lower, only $15 \%$ in a similarly flavoured emulsion. It was not possible to tell from taking the emulsion which oil was being administered, and they were similar in appearance. Serial fatty acid estimations in the control patients (table VI) showed that the olive oil emulsion, in the doses used, did not bring about any significant change in the serum fatty acid levels. Because of the absence of any significant change in serum fatty acid levels as a result of oleate supplementation it is more likely, therefore, that the linoleate supplements afforded a measure of protection during the two years of the trial, rather than that the increased intake of oleate was responsible for the greater number and severity of the relapses in the control group.

Our thanks are due to the Multiple Sclerosis Society for grants in support of this work, the Medical Research Council for their interest and advice in the initiation and design of this trial, and Macarthys Laboratories Ltd. for the preparation of the vegetable oil emulsions. We also wish to thank the pharmacy staif of the two hospitals for their help.

\section{References}

Alling, C., Vanier, M.-T., and Svennerholm, L. (1971). Brain Research, 35, 325.

Allison, R. S. (1963). Proceedings of the Royal Society of Medicine, 56, 71 Arnetoli, G., Pazzagli, A., and Amaducci, L. (1969). Fournal of Neuro-

chemistry, 16, 461.
Baker, R. W. R., Thompson, R. H. S., and Zilkha, K. J. (1963). Lancet, 1,26 .

Baker, R. W. R., Thompson, R. H. S., and Zilkha, K. J. (1964). Fournal of Neurology, Neurosurgery and Psychiatry, 27, 408.

Belin, J., Pettet, N., Smith, A. D., Thompson, R. H. S., and Zilkha, K. J. (1971). Fournal of Neurology, Neurosurgery and Psychiatry, 34, 25.

Caspary, E. A., Prineas, J., Miller, H., and Field, E. J. (1965). Lancet, 2, 1108 .

Clausen, J., and Hansen, I. B. (1970). Acta Neurologica Scandinavica, 46, 1 Cumings, J. N., Shortman, R. C., and Skrbic, T. (1965). Fournal of Clinical Pathology, 18, 641 .

Gerstl, B., Kahnke, M. J., Smith, J. K., Tavaststjerna, M. C., and Hayman, R. B. (1961) Brain, 84, 310 .

Gerstl, B., Eng. L. F., Tavaststjerna, M., Smith, K. J., and Kruse, S. L. (1970). Fournal of Neurochemistry, 17,677.

Gul, S., Smith, A. D., Thempson, R. H. S., Wright, H. P., and Zilkha K.'J. (1970). Fournal of Neurology, Neurosurgery and Psychiatry, 33, 506.

Kurtzke, J. K. (1961). Neurology, 11, 686

Mahler, R. (1971). Unpublished observations.

Millac, P. (1967). Zeitschrift für Nervenheilkunde, 191, 74

Millar, J. H. D., Merrett, J. D., and Dalby, A. M. (1966). Fournal of Neurology, Neurosurgery and Psychiatry, 29, 187.

Millar, J. H. D., Vas, C. J., Noronha, M. J., Liversedge, L. A., and Rawson, M. D. (1967). Lancet, 2, 429.

Payling Wright, H., Thompson, R. H. S., and Zilkha, K. J. (1965). Lancet, 2,1109 .

Sanders, H., Thompson, R. H. S., Payling Wright, H., and Zilkha, K. J. (1968). Fournal of Neurology, Neurosurgery and Psychiatry, 31, 321.

Sinclair, H. M. (1956). Lancet, 1, 381.

Swank, R. L. (1950). American fournal of the Medical Sciences, 220, 421. Swank, R. L. (1970). Archives of Neurology, 23, 460.

Thompson, R. H. S. (1973). Biochemical Society Symposium No. 35

Tichy, J., Vymagal, J., and Michalec, C. (1969). Acta Neurologica Scandinavica, 45, 32 .

Wright, H. Payling (1941). fournal of Pathology and Bacteriology, 55, 255.

\title{
Observations on the Epidemiology of Simple Hypospadias
}

\author{
C. J. ROBERTS, S. LLOYD
}

British Medical fournal, 1973, 1, 768-770

\section{Summary}

A descriptive epidemiological study of simple hypospadias-that is, hypospadias without coexisting malformation outside the genital system-in a birth population of 46,927 singleton males and 1,013 twin males showed that the condition was significantly more common $(P<0.001)$ in uniovular twin males than in either singleton or binovular twin males. Also the temporal distribution of dates of conception had a significant cyclic pattern for each year of the study. Both observations are thought to support the view that gonadotrophin levels at stage 3 sexual organogenesis play an important part in normal masculinization of male external genitalia.

Department of Social and Occupational Medicine, Welsh National School of Medicine, Cardiff CF4 4XN

C. J. ROBERTS, M.D., PH.D., Senior Lecturer

S. LLOYD, B.SC., Scientific Officer

\section{Introduction}

Although the general attitude of the paediatrician has been to regard simple hypospadias as mainly a problem of reconstructive surgery (Aarskog, 1970), there is evidence from workers in experimental embryology, cytogenetics, steroid biochemistry, and neonatal pathology that its importance may be greater than has been hitherto realized. Experiments by Jost (1948, 1965, 1966) in rabbits have shown that the effects of an impairment of testicular function during fetal life depend on two factors: the stage of sexual differentiation at which the impairment is operative-that is the age of the fetus-and the degree of testicular impairment. Bilateral castration of a gonadal male fetus at an early stage results in an entirely female phenotype, whereas impairment of testicular secretory activity at a later stage (produced by decapitation of the fetus) results in hypospadias. Accordingly Jost and others (Campbell, 1963) regarded hypospadias as a mild form of pseudohermaphroditism, the latter being a condition where the gonad is a testis, but in which there are either gross remnants of the Müllerian structures or the appearance of the external genitalia is ambiguous.

In man, the situation is complicated by the fact that the 
placenta as well as the pituitary produces gonadotrophin. High concentrations of human chorionic gonadotrophin (HCG) in the blood of pregnant women coincide with the main period of sexual organogenesis (Wilson et al., 1949; Loraine, 1957). Niemi et al. (1967) found that the maximal output of urinary HCG during pregnancy just precedes maximal enzyme activity in the testes of male fetuses in phase 3 organogenesis-that is, during growth of the external genitalia from 12-16 weeksand they suggested that HCG "may provide a very important stimulus at this time for masculinization of the male fetus." In this connexion Brody and Carlstrom (1965) showed that mothers with male fetuses have a significantly lower level of serum HCG in the last trimester of pregnancy than is the case with female fetuses.

It is generally accepted that the fetus receives most of its gonadotrophin from the placenta. But studies of masculinization of the genital tract of male human fetuses thought to lack a normal functioning adenohypophysis (Ozawa, 1939; Blizzard and Alberts, 1956) as in anencephalics (Tuchmann-Duplessis, 1950; Bearn, 1959) have shown a trend towards hypoplastic external genitalia in these conditions. These observations considered with those made in rabbits by Jost suggest that the fetal pituitary plays a part in the determination of phenotypic sex.

Recently evidence has appeared that an external factor may also be involved in the aetiology of human simple hypospadias. Aarskog (1970) reported an analysis of 80 patients with hypospadias (most of whom had been referred for reconstructive surgery) in which he found that in five there was a history of maternal progestin treatment in early pregnancy. When the position of the urethral meatus was compared to the week of gestation at which progestin treatment was started there seemed to be a relation between the two; the more proximal openings were found in infants of mothers who had been treated in the first month of pregnancy.

In a careful genetic study Sorensen (1953) examined 1,510 relatives of 173 proband families and found a familial occurence in $28 \%$. He also presented data on twin studies-11 pairs from his own study and 10 pairs from Lamy's (1952) material. Eight out of 15 uniovular pairs were concordant, but none of the binovular pairs was so. He concluded that hypospadias was transmitted as a recessive trait with failing manifestation, but added that exogeneous factors (presumably acting as environmental triggers) must also be of importance.

Thus, unlike many other human congenital malformations, not only does much appear to be known about the cause of hypospadias in experimental animals, but a specific teratogen for this defect in humans may have been identified. In this paper we present the descriptive epidemiology of simple hypospadias-that is, excluding cases with coexistent malformations outside the genital system-in a large human birth population (Richards and Lowe, 1971) and relate it to what is already known about the condition from previous clinical and animal studies.

\section{Subjects and Methods}

For the three years beginning 1 January 1964 we have collected information about all infants born to women resident in a defined area in South Wales and about all the congenital defects identified in that birth population. The scope of the investigation and the methods used are described elsewhere (Richards and Lowe, 1971). The area surveyed was defined by the county boundaries of Glamorgan and Monmouthshire and included four county boroughs-Cardiff, Merthyr Tydfil, Newport, and Swansea. For administrative purposes this part of South Wales is divided into 51 local authority areas. During the three years of the investigation 92,982 infants (live and stillborn) were born to women resident in these areas. Of these infants 90,921 were the outcome of singleton pregnancies and of these 46,927 were notified as males. The frequencies of defects quoted in this study are those ascertained by the second anniversary of the birth of the study population.

\section{Results}

During the period of the study there were 93 defects noted as simple hypospadias; 79 were glandular or coronal in site, 13 were penile, and one was perineal. In three subjects (two penile and one perineal) there was some doubt as to whether the baby was male or female but chromosome analysis confirmed that they were all gonadal males. An additional 17 cases (of whom five died within the first month of life) had one or more malformations outside the genital system (we have called these "complicated hypospadias" and have excluded them from the analysis presented in this paper).

Altogether, $79 \%$ of cases were notified by the end of the fourth week (only $2.7 \%$ were discovered as late as $12-14$ months), the source of identification being birth notification $(37 \%)$; obstetric unit $(21 \%)$; paediatrician outside the obstetric unit $(28 \%)$, and others $(14 \%)$. The mean duration of gestation (277.7 days S.D. $22 \cdot 2)$, birth weight $(3 \cdot 2 \mathrm{~kg} \mathrm{S.D.} 0 \cdot 75)$, proportion illegitimate, and proportion stillborn did not differ significantly among notified cases compared with all notified male singletons. The frequency of simple hypospadias was not found to be associated with either parity or maternal age.

Of the 93 cases notified 87 were singleton males (out of a total of 46,927) and six were twin pregnancy males (out of a total of 1,013). Assuming the same rates applied for twins as for singletons the probability of observing six or more twin pregnancy males with hypospadias in our sample is very low, $P \simeq 0.01$ (Poisson model).

Of the six twin males five came from three uniovular twin pairs and one from a binovular M./F. pair. Applying a binovularuniovular ratio of 2.3 to 1 (calculated from the Cardiff Birth Survey 1965-70) to our 1,013 twin pairs we estimated the binovular twin rate to be $1 \cdot 4 / 1,000$ and the uniovular rate to be $16 \cdot 2 / 1,000$. Assuming the same rates for uniovular and binovular twins as for singleton births the probability of observing five or more cases among the uniovular group is extremely low $(P<0.001)$. The binovular rate is not significantly different from the singleton rate. These findings suggest that the risk of simple hypospadias is very much increased (about $8 \frac{1}{2}$ times) in uniovular twin males compared with singletons.

A temporal analysis of the data for the period of the study showed a high frequency peak for winter conceptions which was significant on a simple chi-square; but further analysis showed that the temporal pattern was cyclic (rather than episodic) with a summer trough and a winter peak (the peaks and troughs separated by a six-month period). Two tests of cyclic behaviour were applied to the data and both gave significant results $(P<0.001$ and $P<0.05$ respectively)-these being Edwards's (1961) test of harmonic pattern and the rank sum method (Hewitt et al., 1971). These findings are further supported by a chart of observed over expected monthly frequencies for each year of the study, in which the cyclic pattern is evident for each year's data.

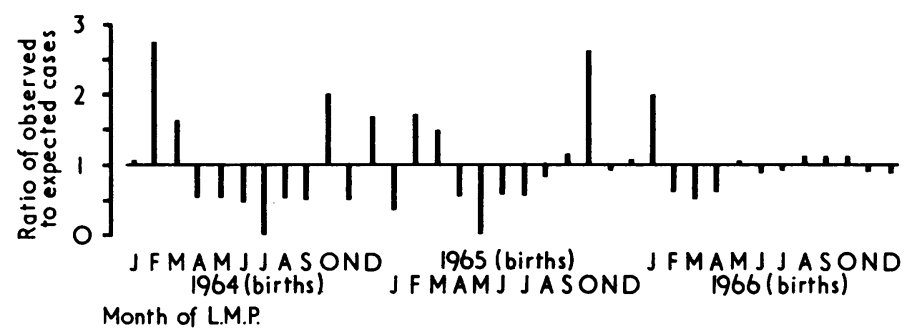

Hypospadias by month of last menstrual period (ratio of observed to expected cases). 


\section{Discussion}

Evidence from familial case studies (Langard, 1884; Kemp, 1943; Schaefer and Erbes, 1950), twin studies (Lehman, 1936; Rhodes, 1943; Lamy, 1953), and Sorensen's (1953) proband study strongly suggest an important genetic component. But reports of discordance in uniovular twins (Camerer, 1938; Lamy, 1952; Sorensen, 1953; present study), evidence from animal studies, and reports that progesterone given in early pregnancy can virilize a female fetus (together with some evidence that it may feminize a male fetus (Aarskog, 1970)) suggest that environmental factors also play an aetiological part.

Considering the findings among twins in this and previous studies, there are two distinct observations, each of which may be important. The first is the discordance in uniovular twins referred to above. The other, to which as yet no reference appears to have been made, is that the condition appears more frequently than would be expected among uniovular male twins. In Lamy's series six pairs were uniovular and only four binovular, in Sorensen's nine were uniovular and two binovular, and in our study three were uniovular and only one binovular. The combined ratio of uniovular to binovular pairs in these three series $(18: 7)$ compared with that found in the Cardiff Birth Survey $(1: 2.3)$ strongly suggests that uniovular twinning and hypospadias are associated. Either the factor which predisposes to uniovular twinning also predisposes to hypospadias or there is something in the nature of uniovular twinning which has a feminizing effect. The peak gonadotrophin output coinciding with phase 3 organogenesis has already been referred to, as has the low serum HCG levels in mothers with male, compared with female, fetuses. The demands of two male fetuses may reduce the HCG levels still further, thus conceivably putting all male twins at risk. It is also possible that in the case of uniovular twins one placenta may not be able to meet the HCG requirements for masculinization of two male fetuses.

The association between season of birth and hypospadias was first studied by Sorensen (1953) in the search for a possible relation between hypospadias and infectious disease in the pregnant mother. He analysed 262 cases and found no evidence of seasonal variation. However, his sample was incomplete, comprised subjects born over a period of at least 60 years, and the analysis was done on dates of birth and not dates of conception. Leck and Record (1966) have shown evidence that length of gestation can vary with season of birth. A recent study by Wehrung and Hay (1970) on 5,145 cases of hypospadias notified on a national basis in the U.S.A. between 1962 and 1965 has also shown a strong association with season of birth. Both studies show similar cyclic patterns with a peak among conceptions whose phase 3 organogenesis occurs during the winter.

The closeness with which the temporal frequency of hypospadias follows a cyclic pattern suggests that the association with season may be direct-that is, with hours of daylight, temperature, or climate (Roberts et al., 1972). The potent action of added illumination on pituitary function (increased day length) was first shown by Rowan (1925) who exposed finches in an outdoor aviary to additional light in the middle of a Canadian winter, thereby producing an increase in gonadal size. In mammals it is thought that the stimulus of light on the retina is transmitted through the optic nerves to alter the secretion of gonadotrophin through the hypothalamus (Clark et al., 1939). It seems not unreasonable at this stage, therefore, to propose a tentative hypothesis that the cyclic pattern evident in South Wales and the U.S.A. derives from the effect of daylight on maternal (and hence fetal) pituitary function. This view is supported by the observation that in both studies peak frequency occurred among conceptions whose phase 3 sexual organogenesis took place in winter. Of the five uniovular twins in our study with hypospadias four were conceived in winter. It would be interesting to know the seasonal frequencies of hypospadias in Arctic and Antarctic communities and areas such as the north of Finland where hours of daylight and hours of darkness have a different distribution from that of countries in more temperate latitudes.

One environmental mechanism has been postulated by Aarskog (1970) who suggested that progestins cause hypospadias by inhibiting the activity of the fetal enzyme 3-hydroxysteroid dehydrogenase, which makes its appearance in the Leydig cells of the testis before any other tissue (irrespective of fetal sex). The appearance of this enzyme is believed to be initiated by HCG and experimental evidence that its inhibition in gonadal males can produce hypospadias has been presented by Goldman and Bongiovanni (1967). Thus maximal proliferation of Leydig cells (believed to produce testosterone), the appearance of enzymes, and the peak levels of blood and urinary gonadotrophin all occur during phase 3 sexual organogenesis. What may be an important association between maternal progestin therapy and resultant pituitary gonadotrophin levels in humans has recently been described by Franchimont (1970), who found that artificial progestins (such as those taken in the oral contraceptive) can significantly reduce circulatory blood levels of the luteinizing hormone component of gonadotrophin in the human subject for periods of up to two months and in some cases even longer.

A consideration of the evidence presented in this paper leads us to propose that feminization of male external genitalia occurs (perhaps in those with a low genetic threshold) when gonadotrophin levels (chorionic or pituitary) are low. We suggest that this situation could arise when a pregnant mother takes progestins early in pregnancy (as treatment for threatened abortion, to induce abortion, or is starting on the pill unaware that she is pregnant) or naturally during winter conceptions or consequent on uniovular twin pregnancy.

\section{References}

Aarskog, D. (1970). Acta Paediatrica Scandinavica, Suppl. No. 203. Bearn, J. G. (1959). Lancet, 2, 464

Blizzard, R. M., and Alberts, M. (1956). Fournal of Pediatrics, 48, 782.

Brody, S., and Carlstrom, G. (1965). fournal of Clinical Endocrinology and Metabolism, 25, 792.

Camerer, J. W. (1938). Erbartz, 5, 105

Campbell, M. F. (1963). In Urology, ed. M. F. Campbell, vol. 2. Philadelphia, Saunders.

Clark, W. E. Le Gros, McKeown, T., and Zuckerman, S. (1939). Proceedings of the Royal Society. Series B. Biological Sciences, 126, 449

Edwards, J. H. (1961). Annals of Human Genetics, 25, 83.

Franchimont, P. (1970). In Reproductive Endocrinology, ed. W. J. Irvine, Edinburgh, Livingstone.

Goldman, A. S., and Bongiovanni, A. M. (1967). Annals of the New York Academy of Sciences, 142, 755.

Hewitt, D., Milner, J., Csima, A., and Pakula, A. (1971). British fournal of Preventive and Social Medicine, 25, 174.

Jost, A. (1948). In Hermaphroditism, Genital Anomalies and Related Endocrine Disorders, ed. H. W. Jones, jun. and W. W. Scott, p. 15. Baltimore, Williams and Wilkins.

Jost, A. (1965). In Organogenesis, ed. R. L. Dettaan and H. Ursprung, p. 611. New York, Holt, Rinehart, and Winston.

Jost, A. (1966). In The Pituary Gland, ed. G. W. Harris and B. T. Donovan, vol. 2. London, Butterworths.

Kemp, T. (1943). Arvelighedslaere, Copenhagen, Munksgaard.

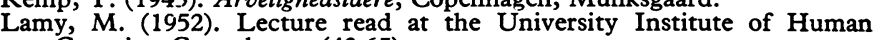
Genetics, Copenhagen (42.65).

Leck, I., and Record, R. G. (1966). British Fournal of Preventive and Social Medicine, 20, 67.

Lehman, W. (1936). Erbartz, 3, 147.

Langard, A. (1884). Lancet, 1,703 .

Loraine, J. A. (1957). Ciba Foundation Colloquia on Endocrinology, 11, 19.

Niemi, M., Ikonen, M., and Hervonen, A. (1967). Ciba Foundation Colloquia on Endocrinology, 16, 31.

Ozawa, M. (1939). Fapanese fournal of Medical Science. Section IV, Pharmacolog $v, 4,189$.

Rhodes, A. (1943). Archives of Paediatrics, 60, 529.

Richards, I. D. G., and Lowe, C. R. (1971). British fournal of Preventive and Social Medicine, $25,59$.

Roberts, C. J., Lloyd, S., and Lowe, C. R. (1972). British fournal of Preventive and Social Medicine, 26, 212 .

and Social Medicine, 26, 212.

Rowan, W. (1925). Nature, 115, 494. American fournal of Surgery, 80, 183.

Schaefer, A. A., and Erbes, J. (1950). American fournal of Surgery, 80, 183.
Sorensen, H. R. (1953). Hypospadias: With Special Reference to Aetiology. Copenhagen, Munksgaard.

Tuchmann-Duplessis, H. (1950). Biologia Neonatorum, 1, 8.

Wehring, D. A., and Hay, S. (1970). British fournal of Preventive and Social Medicine, 24, 24.

Wilson, R. B., Albert, A., and Randall, L. M. (1949). American fournal of Obstetrics and Gynecology, 58, 1. 